$H L A-D R$ and $D Q$ antigen frequencies observed in SLE patients and controls from Singapore

\begin{tabular}{|c|c|c|c|c|}
\hline \multirow[t]{2}{*}{ Antigen } & \multicolumn{2}{|c|}{$\begin{array}{l}S L E \\
(n=26)\end{array}$} & \multicolumn{2}{|c|}{$\begin{array}{c}\text { Controls } \\
(n=77)\end{array}$} \\
\hline & $n$ & $\%$ & $n$ & $\%$ \\
\hline DR1 & 0 & & 0 & \\
\hline DR2 & 7 & 26.9 & 21 & $27 \cdot 3$ \\
\hline $\mathrm{DR} 3$ & 7 & 26.9 & $\star 12$ & $15 \cdot 6$ \\
\hline DR4 & 7 & $26 \cdot 9$ & 17 & $22 \cdot 1$ \\
\hline DR7 & 0 & & 7 & $9 \cdot 1$ \\
\hline DR8 & 7 & 26.9 & 13 & 16.9 \\
\hline DR9 & 9 & $34 \cdot 6$ & 19 & $24 \cdot 7$ \\
\hline DR10 & 1 & 3.8 & 4 & $5 \cdot 2$ \\
\hline DR11 & 2 & $7 \cdot 7$ & 12 & $15 \cdot 6$ \\
\hline DR12 & 5 & $19 \cdot 2$ & 20 & $26 \cdot 0$ \\
\hline DR13 & 1 & 3.8 & 3 & 3.9 \\
\hline DR14 & 1 & $3 \cdot 8$ & 9 & $11 \cdot 7$ \\
\hline DQ2 & 6 & $23 \cdot 6$ & 13 & $16 \cdot 9$ \\
\hline DQ4 & 4 & $15 \cdot 3$ & 9 & $11 \cdot 7$ \\
\hline DQ5 & 7 & $26 \cdot 9$ & 18 & $23 \cdot 4$ \\
\hline DQ6 & 15 & $57 \cdot 7$ & 33 & $42 \cdot 8$ \\
\hline $\mathrm{DQ}^{\star} 0601$ & 10 & $38 \cdot 4$ & 23 & $29 \cdot 9$ \\
\hline $\mathrm{DQ}^{\star} 0602$ & 3 & $10 \cdot 7$ & 7 & $9 \cdot 1$ \\
\hline $\mathrm{DQ}^{\star} 0603-8$ & 2 & $7 \cdot 6$ & 3 & 3.9 \\
\hline DQ7 & 7 & 26.9 & 31 & $40 \cdot 3$ \\
\hline DQ8 & 5 & $19 \cdot 2$ & 8 & $10 \cdot 4$ \\
\hline DQ9 & 8 & $30 \cdot 7$ & 25 & $32 \cdot 5$ \\
\hline
\end{tabular}

$\star \chi^{2}=0.99$; odds ratio $2.0 ; 95 \%$ confidence interval 0.51 to $7.83 ; p=0.09$.

also a non-significant increase in DR8. ${ }^{4}$ However, our most striking finding was the absence of a DR2 association with SLE, as this had been found in the studies from Hong Kong and Korea ${ }^{4}$ and in a further study from Kuala Lumpur, Malaysia. ${ }^{6}$

One possible explanation for these differences could be genetic admixture in the Singapore Chinese population, as there has been some intermarriage with Malays, Indians, and Europeans since the seventeenth century. In contrast, Hong Kong Chinese rarely marry non-Chinese. This could explain the presence in the Singapore SLE patients of the typical white population SLE susceptibility haplotype carrying DR3 and DQ2. Another explanation could be ethnic heterogeneity among the southern Chinese. In Singapore, for example, approximately $75 \%$ of the Chinese migrated from Furjian Province, whereas $90 \%$ or more of the Hong Kong Chinese came from Guangdong Province. Unfortunately, the HLA distributions in these populations are not well characterised, but there may be significant differences which could have implications for the relative frequencies of MHC haplotypes (particularly DR2) predisposing to SLE in these populations.

MARTIN RUDWALEIT KATHRYN GIBSON PAUL WORDSWORTH Nuffield Department of Clinical Medicine, fohn Radcliffe Hospital, Oxford, United Kingdom Queen Elizabeth Hospital, Woodville, Adelaide 5011, Australia
VERNON OH

National University Hospital, Singapore 0511

Correspondence to: Dr P Wordsworth, Nuffield Department of Clinical Medicine, John Radcliffe Hospital, Oxford OX3 9DU, United Kingdom.

$M$ Rudwaleit is supported by the Deutschen Akademischen Austauschdienst (DAAD). The authors are grateful for the financial support of the Arthritis and Rheumatism Council.

1 Deapen D, Escalante A, Weirib L, et al. A revised estimate of twin concordance in systemic lupus erythematosus. Arthritis Rheum 1992; 35: 311-7.

2 Hartung K, Baur M P, Coldeway R, et al. Major histocompatibility complex haplotypes and complement $\mathrm{C} 4$ alleles in systemic lupus erythematosus. 7 Clin Invest 1992; 90: 1346-51.

3 Davies E J, Hillerby M C, Cooper R G, et al. HLA-DQ, DR and complement C4 variants in systemic lupus erythematosus. $\mathrm{Br} \mathcal{F}$ Rheumatol 1993; 32: 870-5.

4 Hong G H, Kim H Y, Takeuchi F, et al. Association of complement C4 and HLA-DR alleles with systemic lupus erythematosus in Koreans. $\mathcal{f}$ Rheumatol 1994; 21 : 442-7.

5 Hawkins B R, Lam Wong K, Wong R W S, Ho Chan $K$, Dunckley $H$, Serjeantson $S W$ Chan K, Dunckley $H$, Serjeantson $S$. Strong association between the major histoerythematosus in southern Chinese. $f$ Rheumatol 1987; 14: $1128-31$.

6 Doherty D G, Ireland R, Demaine A G, et al. Major histocompatibility complex genes and susceptibility to systemic lupus erythematosus in southern Chinese. Arthritis Rheum 1992; 35: 641-6.

7 Wordsworth B W, Allsopp C E M, Young R P, Bell J I. HLA-DR typing using DNA amplification by the polymerase chain reaction and sequential hybridization to sequence-specific oligonucleotide probes. Immunogenetics 1990; 32: 413-8.

8 Bunce M, Taylor C J, Welsh K I. Rapid HLADQB typing by eight PCR amplifications with sequence-specific primers (PCR-SSO). Hum Immunol 1993; 37: 201-6.

\section{Treatment of refractory reflex sympathetic dystrophy with pamidronate}

Reflex sympathetic dystrophy (RSD) is a condition affecting part or the whole of a limb, and is characterised by pain, vasomotor disturbance and trophic changes. RSD can persist for months or years and be severely disabling. ${ }^{1}$ On radiographs, it is characterised by local osteoporosis, which corresponds to osteoclast hyperactivity. Calcitonin, an antiosteoclastic drug, has been shown to help some patients. ${ }^{2}$ Pamidronate, a second generation biphosphonate, is a potent antiosteoclastic agent, ${ }^{3}$ which is the rationale for using it in the treatment of RSD.

In an open prospective study, we evaluated the efficacy of pamidronate in the treatment of refractory RSD. Eleven patients (three men and eight women; mean age 51.3 (SD 12.8) years) suffering from RSD of at least six months duration (mean of 14.6 $(10 \cdot 3)$ months), refractory to calcitonin and physical therapy, were included. All patients fulfilled Doury's criteria for the diagnosis of RSD. ${ }^{4}$ The involved sites were the foot $(n=5)$, the hand $(n=2)$, the upper limb $(n=2)$, the knee $(n=1)$, the lower limb $(n=1)$. In eight cases, the RSD was related to local injury. Six patients had had to stop work because of RSD.

Radiographs of the affected sites showed osteopenia in all cases. The patients were given $30 \mathrm{mg}$ of intravenous pamidronate in $500 \mathrm{ml}$ of saline over four hours, daily, for three consecutive days. The patients received no standard treatment for their RSD from one month before the administration of pamidronate until three months after it. Patients were assessed by the same observer at baseline and after one and three months. Evaluation consisted of a visual analogue scale for pain (VAS), and a physician global assessment (no improvement, moderate, significant or excellent improvement) based on objective signs on clinical evaluation (hyperhydrosis, vasomotor changes, joint stiffness). Blood cell count and serum calcaemia (corrected with serum albuminaemia) were measured before, during, and one and three days after the administration of pamidronate.

The mean VAS decreased from $58 \cdot 8 / 100$ $(20 \cdot 2)$ before therapy, to $41 \cdot 1 / 100(26 \cdot 8)$ at one month $(\mathrm{p}<0.05$; Wilcoxon paired test) and $33 \cdot 8 / 100(29)$ at three months $(p<0.01)$. In the physician global assessment, the results were: no improvement $(n=4)$, moderate improvement $(n=1)$, significant improvement $(n=3)$, and excellent improvement $(n=3)$ at one and three months. Three of the six patients who had had to stop work had returned to work after three months. We were unable to find predictive factors for efficacy (age, gender, affected site, degree of osteopenia). Pamidronate was well tolerated, apart from classical minor adverse effects: two patients had a transient fever, two patients had brief, asymptomatic hypocalcaemia $(2.05 \mathrm{mmol} / \mathrm{l})$ and one patient had hypocalcaemia $(2 \mathrm{mmol} / \mathrm{l})$ associated with perioral paraesthesia which resolved rapidly with oral calcium treatment ( $1 \mathrm{~g} /$ day).

It is not possible to say whether the observed improvements were attributable to the treatment, the natural history of the disease, or psychological factors, as pamidronate was not compared with placebo in a double blind trial. However, more than $50 \%$ of the patients suffering from chronic disease, previously refractory to treatment, showed significant or excellent improvement while taking pamidronate, suggesting that it was effective.

In conclusion, this study suggests that pamidronate is a safe and effective drug for the treatment of some refractory cases of RSD. Further double blind trials are required to confirm these results.

JEAN FRANCIS MAILLEFERT
CHRISTINE CHATARD
SUSANNAH OWEN
THIERRY PEERE
CHRISTIAN TAVERNIER
Department of Rheumatology,
Hopital Général, Dijon, France

JACQUES TEBIB

Department of Rheumatology,

Pierre Benite, France

Correspondence to: $\mathrm{Dr} J \mathrm{~F}$ Maillefert, Service de
Rhumatologie, Hôpital Général, 3 rue du Fb Rhumes, 21000 Dijon, France.

1 Chard M D. Diagnosis and management of algodystrophy. Ann Rheum Dis 1991; 50: $727-30$

2 Gobelet C, Meier J L, Schaffner W, BischoffDeloye A, Gerster J C, Burckhardt P. Calcitonin and reflex sympathetic dystrophy syndrome. Clin Rheumatol 1986; 5: 382-8.

3 Fitton A, McTavish D. Pamidronate. Drugs 1991; 41: 289-318.

4 Doury P, Dirheimer Y, Pattin S. Algodystrophy. Berlin, Heidelberg, New York: Springer, 1981.

\section{Pericardial tamponade preceding cutaneous involvement in systemic sclerosis}

Cardiac involvement in systemic sclerosis may be primary, or secondary to involvement of other organ systems. Primary cardiac involvement in systemic sclerosis may be manifested as pericardial disease, myocardial disease, conduction system abnormalities, or cardiac arrhythmias. ${ }^{1}$ Cardiac symptoms do not usually appear until late in the disease, but exceptionally may precede the recog- 